\title{
Counting on working memory in arithmetic problem solving
}

\author{
ROBERT H. LOGIE, KENNETH J. GILHOOLY, and VALERIE WYNN \\ University of Aberdeen, Aberdeen, Scotland, United Kingdom
}

\begin{abstract}
Mental calculation is an important everyday skill involving access to well-learned procedures, problem solving, and working memory. Although there is an active literature on acquiring concepts and procedures for mental arithmetic, relatively little is known about the role of working memory in this task. This paper reports two experiments in which dual-task methodology is used to study the role of components of working memory in mental addition. In Experiment 1, mental addition of auditorily presented two-digit numbers was significantly disrupted by concurrent random letter generation and, to a lesser extent, by concurrent articulatory suppression, but was unimpaired by concurrent hand movement or by presentation of irrelevant pictures. Although the number of errors increased with two of the dual tasks, the incorrect responses tended to be quite close to the correct answer. In Experiment 2, the numbers for addition were presented visually. Here again, random generation produced the largest disruption of mental arithmetic performance, while a smaller amount of disruption was observed for articulatory suppression, hand movement, and unattended auditorily presented two-digit numbers. The overall levels of performance were better and the absolute size of the disruptive effects shown with visual presentation was very small compared with those found for auditory presentation. This pattern of results is consistent with a role for a central executive component of working memory in performing the calculations required for mental addition and in producing approximately correct answers. Visuospatial resources in working memory may also be involved in approximations. The data support the view that the subvocal rehearsal component of working memory provides a means of maintaining accuracy in mental arithmetic, and this matches a similar conclusion derived from previous work on counting. The general implications for the role of working memory in arithmetic problem solving will be discussed.
\end{abstract}

The concept of working memory is commonly invoked as a mechanism for the processing and temporary storage of information in a wide variety of cognitive tasks. For example, the limitations of working memory are often claimed to place constraints on reasoning tasks (e.g., Gilhooly, Logie, Wetherick, \& Wynn, 1993; Johnson-Laird, 1983; Johnson-Laird \& Byrne, 1991), problem solving (e.g., Gilhooly, 1988; Johnstone \& AlNaeme, 1991; Newell \& Simon, 1972), and comprehension (Just \& Carpenter, 1992). The terms working memory and short-term memory are also used in studies of calculation and counting (e.g., Healy \& Nairne, 1985; Hitch, 1978; Logie \& Baddeley, 1987; Widaman, Geary, Cormier, \& Little, 1989). However, relatively few studies specify in detail the nature of the memory system involved or the nature of the constraints for which working memory is held responsible. In this paper, we address this issue by investigating the detailed role of working memory in the area of mental arithmetic.

This paper was prepared in part while Robert $H$. Logie was a visiting professor at the Department of Psychology, University of North Carolina at Greensboro. The support of that institution and particularly of Marc Marschark is gratefully acknowledged. The authors are grateful to Mark Ashcraft and Keith Widaman for helpful comments on an earlier draft of this paper. Correspondence should be addressed to R. H. Logie, Department of Psychology, University of Aberdeen, Kings College, Aberdeen AB9 2UB, Scotland.

\section{Calculation and Counting}

Mental arithmetic is an important everyday skill that is a key component of an elementary education. There is an established literature on the topic that has examined arithmetic and counting in both normal and braindamaged adults and children (e.g., Ashcraft, 1992; Ashcraft \& Stazyk, 1981; Dehaene, 1992; Ellis \& Hennelley, 1980; Gallistel \& Gelman, 1992; Geary \& Widaman, 1987; Healy \& Nairne, 1985; Hitch, 1978; Hitch \& McAuley, 1991; Logie \& Baddeley, 1987; McCloskey, Sokol, \& Goodman, 1986; Sokol, McCloskey, Cohen, \& Aliminosa, 1991; Widaman et al., 1989). From these and other studies it has become clear that mental arithmetic involves well-learned procedures, problem-solving skills, and reliance on short-term or working memory. A number of relatively sophisticated models of cognitive processing in arithmetic have been developed to account for access to arithmetic knowledge and skills. A common view is that normal adults have available a vocabulary of known sums, products, and so on, which are organized in the form of an associative semantic network that capitalizes on the brain mechanisms involved in processing language (e.g., Campbell \& Graham, 1985; Dehaene, 1992; McCloskey, Harley, \& Sokol, 1991). Thus, for example, most adults know the answer to the sum $6+7$ or the product $3 \times 4$, without having to follow any form of calculation algorithm. The an- 
swers to these problems are learned by association, thus allowing for direct memory access. In the case of arithmetic problems that cannot be tackled in this way by most people (e.g., $234+429$ or $23 \times 47$ ), more complex models have been developed that specify stages in the calculation. However, there is a continuing debate among the authors of the various models as to the nature of the cognitive processing that might be involved (e.g., Campbell \& Clark, 1988; Dehaene, 1992; Geary \& Widaman, 1992; McCloskey, 1992; McCloskey et al., 1991; McCloskey et al., 1986; Sokol, GoodmanSchulman, \& McCloskey, 1989; Sokol et al., 1991; Widaman et al., 1989) or how the necessary skills are acquired and applied by young children (Gallistel \& Gelman, 1992; Graham, 1987; Hitch, Cundick, Haughey, Pugh, \& Wright, 1987; Siegler, 1987). Despite the debate, most researchers in this area agree that there is a requirement for temporary storage of information during calculation in addition to any other processes that might be involved. Even in the case of "direct access" to a solution, the individual has to retain, on a temporary basis, the individual items that have to be summed or multiplied. For example, Hitch (1978) demonstrated that a number of errors in mental arithmetic occur because subjects fail to retain in working memory an accurate record of "carries" and interim solutions. Also, in some of their more complex problems, Widaman et al. (1989) refer to the use of short-term memory and to the use of "a relatively slow, implicit speech process" (p. 914) in components of the calculation process. Yet in these studies and elsewhere, the exact nature and extent of the short-term memory involvement or the "implicit speech process" remains underspecified. Moreover, although the nature of the cognitive processing involved in counting and calculation has been discussed in some detail, there has been very little discussion of the kind of cognitive mechanisms that might support these processes.

\section{Working Memory}

The notion of a single, flexible, short-term memory system has in recent years largely been replaced in the literature by the concept of working memory. It is now well established that there are likely to be a number of components of the cognitive architecture that are responsible for different forms of processing and temporary storage, and working memory often serves as a collective term for these various components. One coherent model of working memory that has been singularly successful in accounting for a wide range of data is that developed by Baddeley and his colleagues (e.g., Baddeley, 1986, 1992; Baddeley \& Hitch, 1974). This model comprises three components, a central controlling executive considered to be involved in on-line cognitive processing, such as problem solving and calculation, and in coordinating the activities of the other two more specialized components (see, e.g., Baddeley, 1986; Gilhooly et al., 1993; Logie, 1993). One of these components, known as the articulatory loop is involved in temporary storage of verbal information (e.g., Baddeley \& Logie, 1992; Baddeley, Thomson, \& Buchanan, 1975; Salamé \& Baddeley, 1982). Another component, known as the visuospatial scratch pad, serves a similar temporary storage function for visual and spatial material (Baddeley \& Lieberman, 1980; Farmer, Berman, \& Fletcher, 1986; Logie, 1986, 1989, 1991).

There is now a considerable body of evidence suggesting that the articulatory loop comprises two subsystems: an active subvocal rehearsal process and a passive phonologically based store (see, e.g., Baddeley, 1992; Baddeley \& Logie, 1992). The rehearsal process is in the form of subvocal articulation and is closely linked with the speech production system. The contents of the passive store are subject to decay, but can be refreshed and maintained by subvocal rehearsal. Evidence for this view comes in part from the fact that when subjects are required to suppress articulation by repeating aloud an irrelevant speech sound, such as "blah, blah, blah" or "the, the, the," this disrupts temporary memory for sequences of verbal items, such as digits or words (e.g., Baddeley, Lewis, \& Vallar, 1984; Levy, 1971; Murray, 1968). The evidence for phonological coding derives from the finding that phonologically similar material is recalled less accurately than is phonologically distinct material. This finding is obtained when subjects are required to read or to listen to the items for recall (e.g., Conrad, 1964). Suppressing articulation removes the effect of phonological similarity for visually presented material; this suggests that subvocal articulation is involved in translating visually presented verbal material into a phonological code (Baddeley et al., 1984). Finally, when subjects are presented with a tape of irrelevant speech during a verbal short-term memory task, their ability is impaired for recall of visually presented verbal material. This impairment is more pronounced when the irrelevant speech is phonologically similar to the material for recall, again supporting the notion that verbal information generally is stored in a phonological form. This "irrelevant speech effect" also suggests that the speech appears to have direct access to the phonological store, thereby causing disruption of its contents (Salamé \& Baddeley, 1982).

Evidence for the characteristics of the visuospatial component of working memory suggests that it too appears to comprise two subsystems: one that retains visual material, such as color and shape, and one that retains spatial information, such as movements through space (see, e.g., Glasgow \& Papadias, 1992; Logie, 1986, 1989, 1991; Logie \& Baddeley, 1990; Logie \& Marchetti, 1991; Logie, Zucco, \& Baddeley, 1990; Quinn \& Ralston, 1986; Reisberg \& Logie, 1993; Smyth $\&$ Pendleton, 1989). For example, there is some evidence to suggest that temporary retention of visual information is disrupted by irrelevant visual input but not by concurrent hand tapping or arm movement. In contrast, retention of spatial material appears to be disrupted 
by concurrent arm movement but not by concurrent irrelevant visual input (e.g., Brooks, 1967; Logie, 1986; Logie \& Marchetti, 1991; Matthews, 1983; Quinn \& Ralston, 1986; Smyth \& Pendleton, 1989). However, this is still a developing area, and the evidence is by no means conclusive. Nevertheless, the distinction between the mechanism responsible for temporary storage of visual and spatial information and that for verbal information (the articulatory loop) is well established (e.g., Brooks, 1967; Farmer, Berman, \& Fletcher, 1986; Logie et al., 1990; Wickens \& Liu, 1988).

Evidence for the characteristics of the central executive is accumulating, and its role as coordinator of the slave systems has empirical support (Baddeley, Bressi, Della Sala, Logie, \& Spinnler, 1991; Baddeley, Logie, Bressi, Della Sala, \& Spinnler, 1986). A similar concept has arisen in studies of divided attention where this function is referred to as a cost of concurrence (Navon \& Gopher, 1979) or as an executive time sharer (Hunt \& Lansman, 1982; McLeod, 1977; Moray, 1967; Yee, Hunt, \& Pellegrino, 1991). In contrast, the functioning of the central executive in reasoning and problem solving has been tackled in only a few studies (Farmer et al., 1986; Gilhooly et al., 1993; for discussions, see Della Sala \& Logie, 1993; Logie, 1993), although recent studies of comprehension refer to a concept very similar to that of the central executive (e.g., Just \& Carpenter, 1992). ${ }^{1}$ In studies of neuropsychological patients, tasks such as card sorting are commonly referred to as relying on executive functions, requiring focused attention, planning, and control (e.g., Milner, 1963; for discussions, see Della Sala \& Logie, 1993; McCarthy \& Warrington, 1990; Shallice, 1988). The involvement of the central executive in tasks such as card sorting or more complex cognitive tasks appears to be disrupted by the use of a technique known as random generation (Baddeley, 1966). In this procedure, subjects are asked to generate items from a well-known set, such as the alphabet or the digit set 0 through 9 . It is a task that requires subjects to keep track of the number of times each item has been generated and to inhibit well-known sequences such as "ABCD" or "3456." These are cognitive demands that would indeed appear to rely on planning and control functions (Evans, 1978; Treisman \& Faulkner, 1987). It has been shown to disrupt performance in syllogistic reasoning tasks (Gilhooly et al., 1993) and in complex dynamic tasks that place heavy demands on cognitive resources (Fabiani et al., 1989; Logie \& Salway, 1990; Salway, 1991).

It will be clear from this brief overview of the literature that a common approach in the development of working memory has been to use dual-task methodology. This approach has also been successful in identifying which components of working memory are involved in performing cognitive tasks (Gilhooly et al., 1993; Logie, Baddeley, Mane, Donchin, \& Sheptak, 1989; Saariluoma, 1991). The logic of this approach is that first we identify simple secondary tasks that have been shown empirically to place heavy loads on individual components of working memory, and then we ask subjects to perform a concurrent cognitive task and assess the pattern of impairment or sparing of performance that obtains. This pattern then allows us to identify which, if any, of the components of working memory are involved in performing the cognitive task. Thus, for example, articulatory suppression (described above) appears to load the subvocal rehearsal component of the articulatory loop, without having any effect on visuospatial storage. Irrelevant speech appears to disrupt the operation of the phonological store, random generation disrupts the central executive, and tapping and irrelevant visual input disrupt the visuospatial system in working memory.

\section{Working Memory in Counting and Arithmetic}

Some of our previous work has shown the componentbased dual-task approach (described above) to be fruitful in studying counting (Logie \& Baddeley, 1987). In these studies, subjects were required to count the number of dots in a random array or to count the number of times a square appeared at irregular intervals on a computer screen and respond with the total using a numeric keypad. Results were consistent in showing that articulatory suppression during counting produced a substantial disruption of counting performance. However, the major disruptive effect of suppression was on the number of errors produced rather than the size of the error. When a subject made an error, it tended to be numerically quite close to the correct total, suggesting that performance was not totally disrupted by articulatory suppression. We also observed an effect of irrelevant speech, which was more prevalent when the speech was phonologically similar to the numbers being counted (tun, woo, tee, sore, thrive, etc.; Salamé \& Baddeley, 1982). However, although the effect was statistically reliable, it was very small and certainly much weaker than the disruption associated with articulatory suppression. The irrelevant speech effect was not much larger even when the speech comprised random two-digit numbers. This was a surprising result, not least because of anecdotal reports as to the disruptive effects of background speech on everyday tasks involving counting. There was no disruptive effect of a concurrent hand movement task. We tentatively interpreted these results in terms of two separate components of the counting task: subvocalization of a running total, and priming of the most recently accessed numbers in long-term memory. The contrast between the effects of irrelevant speech and articulatory suppression is consistent with the suggestion that subvocalization of the running total plays a more central role in counting than does the phonology of the words used for the number system (Healy \& Nairne, 1985; Nairne \& Healy, 1983).

We mentioned above that Widaman et al. (1989) incorporated the idea of a relatively slow subvocal speechbased process in their more complex arithmetic tasks. There is other evidence for the importance of subvocal 
articulation in arithmetic and counting. For example, Ellis and Hennelley (1980; see also Ellis, 1992) showed that arithmetic performance and verbal memory span in children speaking the Welsh language are poorer than if those same children perform the tasks in English. This phenomenon does not arise from differential familiarity with the respective languages but is accounted for by the time taken to pronounce the words in each language. Words that take longer to pronounce also take longer to subvocalize, thus placing a heavier demand on the subvocal rehearsal mechanism. Similar cross-language contrasts in digit span, counting, and arithmetic have been shown, comparing a variety of languages, such as Chinese and English (Hoosain \& Salili, 1988), Arabic, Hebrew, Spanish, and English (Naveh-Benjamin \& Ayres, 1986), and Italian and English (Della Sala \& Logie, 1993). Further evidence is provided by Gonzalez and Kolers (1982), who demonstrated that the surface characteristics of the number system used (in their case, Arabic vs. Roman number systems) can have a significant impact on mental calculation.

Some authors have suggested that visual imagery may also be involved in mathematics, and this opens the possibility of some involvement of the visuospatial component of working memory. For example, Hayes (1973) demonstrated how subjects could use visual images to assist in the solution of mathematical problems. However, in his studies, subjects were encouraged to use visual imagery in solution of algebraic problems. It is not clear from his data the extent to which people spontaneously rely on visual imagery across different kinds of arithmetic problems. Moyer and Landauer (1967) and Restle (1970) argued that, in the case of mental addition, subjects use a mental analogue of a number line, which is then extended in their mental representation by an amount equivalent to the addend. This allows the subject to "read off" the answer from the resulting analogue image. More recently, this view has been extended, for example, by Dehaene (1992), who suggests that an analogue magnitude representation can be used for arriving at approximate solutions to arithmetic problems. This process of approximation is viewed as distinct from quantification, which is associated more closely with accuracy in numerical cognition. This distinction between accuracy and approximation has cropped up in studies of children's mathematics (Reyna \& Brainerd, 1993) and fits with the interpretation of our own findings on the effects on counting of articulatory suppression (Logie \& Baddeley, 1987). However, the extent to which people spontaneously rely on visuospatial temporary storage or visual imagery is still very much in debate. Indeed, it may be that imagery offers one of a number of strategies available and that only some individuals would choose to use imagery in laboratory studies of mental arithmetic (e.g., Siegler, 1987).

Finally, the nature of the hypothesized central executive suggests that it ought to have a central role in numerical cognition, particularly in the case of more com- plex arithmetical problems, although as yet there is scant evidence for this assumption. It is clear that whether working memory has anything more than a peripheral role to play in numerical cognition is still an open question, and the empirical studies reported in this paper attempted to address this issue. Two experiments are reported, both of which investigated mental addition of two-digit numbers. The arithmetic tasks were coupled with a range of concurrent secondary tasks to explore the possible role of the various components of working memory that we discussed above. In Experiment 1, subjects heard the numbers for mental addition, and the involvement of subvocal articulation was investigated by using articulatory suppression. The visuospatial workingmemory component was studied using irrelevant pictures and concurrent hand movement. Random generation of letters of the alphabet was used to investigate the extent to which arithmetic depends on central executive processes. With auditory presentation of the numbers for adding, it is impractical to investigate the possible disruptive effects of concurrent irrelevant heard speech, a manipulation that produced a rather surprising lack of interference in our previous experiments on counting (Logie \& Baddeley, 1987). Therefore, in Experiment 2, the numbers for addition were presented visually, and the possible role for the phonological store was studied with auditory presentation of irrelevant words. In this second experiment, we also studied the effects of articulatory suppression, hand movement, and random letter generation.

\section{EXPERIMENT 1}

\section{Mental Arithmetic With Auditory Presentation}

\section{Method}

Subjects. A total of 24 subjects participated in this experiment (14 females and 10 males). All were members of the Psychology Department Volunteer Subject Panel, comprising members of the general public. Their ages ranged from 18 to 65 years, with a mean of 45 years.

Arithmetic task. The arithmetic task involved adding a series of two-digit numbers, which were presented through headphones over a period of $20 \mathrm{sec}$. The subjects were requested to maintain mentally a running total of the addition, but only to report aloud the final total when the complete series had been presented. We were aware that subjects vary widely in their competence with mental arithmetic, and this was confirmed in a pilot study. We were anxious to avoid potential difficulties in interpreting data from subjects performing tasks that were too demanding or too simple, resulting in large intersubject performance variability or floor and ceiling effects in our data. This problem arises in studies of short-term verbal memory where subjects vary in ability. In those cases, a common technique is to use a memory span procedure to equate task difficulty across subjects (e.g., Baddeley et al., 1991; Baddeley et al., 1986). Therefore, the number of two-digit additions was initially adjusted according to the arithmetic competence of each subject, using an arithmetic span procedure. The span procedure involved presenting the subjects initially with two two-digit numbers, which they were to add mentally; they were requested to report aloud the total as quickly and as accurately as they could. They were then given a third two-digit number, which they were to add to the previous total; they then reported aloud the 
new total. This continued either for a maximum of six two-digit numbers or when $20 \mathrm{sec}$ had elapsed, whichever came first. This procedure was repeated three times. The arithmetic span for each subject was taken as the mean number of accurate additions completed within the 20 -sec period.

Thus, in the main task, a given subject could be presented with $3,4,5$, or 6 two-digit numbers to add, depending on their adding ability as measured by our arithmetic span procedure. In all cases, the numbers for a given sequence were presented within a $20-\mathrm{sec}$ period according to the timing schedule shown in Table 1 . The numbers of subjects presented with each series length are shown in the same table. Each subject was presented with a total of 40 problems, split into two sets of 20 problems. For each subject, one set was performed as a single task, and the other set of 20 problems was completed along with one of four different secondary tasks (described below). The subjects were allocated to each of the four groups so as to ensure that the groups did not differ in mean age or adding span. An analysis of variance (ANOVA) across the groups indicated that the subjects were matched on these variables ( $F<1$, in both cases). All of the problems were presented via headphones from a tape recorder with different tapes used for 3-, 4-, 5-, or 6-number sequences. Half of the problems (10) in each condition had a maximum of two carries involved: for example, $13+18(31)+13(44)+21(65)+13(78)+25(103)$. For sequences of less than 6 numbers, the problems involved only one carry, which occurred on the first addition. In fact, only 1 subject achieved an arithmetic span of six (see Table 1); we therefore referred to these as single-carry problems. For the other half of the problems, each addition in the sequence involved a carry: for example, $29+$ $18(47)+48(95)+22(117)+18(135)+27(162)$. These were referred to as multiple-carry problems. In the latter case, one addition in each problem sequence involved a carry that was in the "tens" column rather than in the "units" column (in the example above, $95+22$ ). We felt, however, that the distinction in the number of carries for the two problem types was sufficient to examine number of carries as a factor in our experimental design, with the multiple-carry problems perhaps placing a greater demand on working memory than would the single-carry problems (Ashcraft, Donley, Halas, \& Vakali, 1992; Hitch, 1978).

The two different kinds of problems were presented randomly within each set of 20 problems. The same random order of problems within each set was used for all subjects, but the allocation of a given set to the single- or dual-task condition was counterbalanced across subjects. On each trial, the subject heard a warning beep on the tape $3 \mathrm{sec}$ before the first number was presented. Immediately following presentation of the last number in the series, the subjects heard a beep and were given $7 \mathrm{sec}$ in which to respond with their total for the number sequence before they heard the warning beep for the start of the next trial. Throughout all trials, the subjects heard a regular metronome tick at one per second. This was also present in the dual-task conditions (see below), and it was included in the adding-alone single-task condition to ensure that any secondary task interference could not be attributed to the distracting effect of a metronome beat.

The secondary tasks were chosen to involve different components of the working-memory system and comprised articulatory suppression, random generation, irrelevant pictures, and hand movement. Each of these secondary tasks is described below. With the exception of the irrelevant pictures condition, subject performance was measured on each of the secondary tasks performed on its own as well as when performed concurrently with mental addition. Given the nature of dual-task performance, we were concerned that the subjects would become overly fatigued or would improve with practice if all subjects were required to carry out the addition task under all five experimental conditions (control plus four dual-task conditions). The subjects might, for example, alter their strategy in the course of the experiment (e.g., Della Sala, Logie, Marchetti, \& Wynn, 1991; Siegler, 1987) if they had extensive experience of the experimental procedure. The subjects were split into four groups of 6 subjects, with each group corresponding to one of the secondary tasks. That is, Group 1 performed adding alone and adding plus articulatory suppression, Group 2 performed adding alone and adding plus random generation, Group 3 performed adding alone and adding plus irrelevant pictures, and Group 4 performed adding alone and adding plus tapping. This is a design that we have used successfully in previous studies that have used a range of secondary tasks (Gilhooly et al., 1993). Half of the subjects in each group performed the control, adding task first followed by adding plus a secondary task; half performed the conditions in the reverse order.

Articulatory suppression. We investigated the role of subvocal rehearsal in the mental arithmetic task by asking the subjects to repeat the word the once per second throughout presentation of the series of numbers. The rate of articulation was indicated by a metronome beat once every second throughout each trial. Articulatory suppression started in time to the metronome at the onset of the warning beep $3 \mathrm{sec}$ prior to the presentation of the first twodigit number in each sequence, and continued until the subject responded orally with the final total. In addition, the subjects were asked to perform the articulatory suppression task on its own for 1025 -sec periods, so as to provide a measure of control performance on this task. The subjects' articulations were monitored by a throat microphone and a voice key connected to an Atari computer, which recorded articulation times. This allowed us to measure whether the subjects successfully maintained a rate of one response per second.

Random generation. The role of the central executive component of working memory was studied using random generation of letters of the alphabet. The subjects were to say aloud a letter of the alphabet at a rate of one per second and in as random a fashion as they could. The rate was indicated by a metronome that continued throughout the trial. To assist the subjects in understanding

Table 1

Timing (in Seconds) and Number of Subjects for Presentation of Sequences of 3, 4, 5, and 6 Two-Digit Numbers in Experiment 1 (Auditory Presentation) and Experiment 2 (Visual Presentation)

\begin{tabular}{ccccccccc}
\hline & \multicolumn{9}{c}{\begin{tabular}{c} 
Timing \\
\multirow{2}{*}{$\begin{array}{l}\text { Sequence } \\
\text { Length }\end{array}$}
\end{tabular}} & 1st & 2nd & 3rd & 4th & 5th & 6th & & \multicolumn{2}{c}{$\begin{array}{c}\text { Number of Subjects } \\
\text { Auditory }\end{array}$} & $\begin{array}{c}\text { Visual } \\
\text { (Exp. 1) }\end{array}$ & (Exp. 2) \\
\hline 3 & 1 & 4 & 12 & & & & 4 & 3 \\
4 & 1 & 3 & 9 & 15 & & & 13 & 11 \\
5 & 1 & 3 & 7 & 11 & 15 & & 6 & 10 \\
6 & 1 & 3 & 6 & 9 & 12 & 15 & 1 & 0 \\
\hline
\end{tabular}

Note--Timings were taken from the initial warning signal at the start of each trial. 
what was required, this task was likened to picking out a letter at random from a hat, then replacing it in the hat and picking out a letter again. Thus, a given letter was as likely to be picked out again as any other letter. They were also asked to avoid stereotype sequences, such as A-B-C-D, or spelling out words. Otherwise, the procedure for the task was identical to that for articulatory suppression, except that responses were recorded on tape in addition to being timed via the voice key and computer. We recorded the actual responses made by the subject in order to assess the degree of randomness achieved; however - to anticipate our results - the subjects produced too few responses in the dual-task condition to allow us to perform this analysis. As for the other secondary tasks, the subjects were asked to perform the random-generation task on its own for 1025 -sec periods to give a measure of single-task control performance.

Irrelevant pictures. This task was included to determine whether or not visual imagery is heavily involved in mental arithmetic. Irrelevant pictures in the form of line drawings of objects and animals were projected by a shide projector onto a screen approximately $2 \mathrm{~m}$ in front of the subject and at a rate of one slide every $1.5 \mathrm{sec}$ throughout each trial. The projected pictures were approximately $1.5 \times 1.5 \mathrm{~m}$. Presentation of the pictures started with the warning beep $3 \mathrm{sec}$ before the subjects heard the first two-digit number and stopped when the subject responded with the final total. The subjects were instructed to simply keep their eyes open and looking in the direction of the pictures. There was also a video camera directed toward the subjects' eyes as an incentive to follow instructions. However, unknown to the subject, no actual video recording was taken.

Hand movement. This task was included to test for the possible involvement of spatial manipulation of images. With their preferred hand, the subjects had to press in sequence each of four buttons. The buttons were in the form of four sprung switches arranged in a square on a $190 \times 190 \mathrm{~mm}$ wooden board. The buttons and the subject's hand were hidden from the subject's view to ensure that this was primarily a spatial rather than a visual secondary task. This follows the procedure used in previous studies of spatial imagery (Baddeley \& Lieberman, 1980; Farmer et al., 1986; Quinn \& Ralston, 1986). The buttons were to be pressed at a rate of one per second in response to the metronome that continued throughout the trial. The rate of pressing was recorded by an Atari microcomputer connected to the buttons. When performing the task concurrently with arithmetic, the subjects commenced hand movement $3 \mathrm{sec}$ prior to presentation of the first number in the series and stopped when the subject responded with the correct total. In addition, the subjects performed the movement task on its own for 10 separate periods of $25 \mathrm{sec}$ to assess control levels of performance.

\section{Results}

Performance on mental addition. Arithmetic performance was measured in terms of both the number of incorrect totals reported by subjects and the size of their errors.

Looking first at number of errors (incorrect totals), the data for each subject were entered into a three-way mixed design ANOVA, with groups (4 levels) as a between-subject factor, and single versus dual task ( 2 levels) and single- versus multiple-carry problems (2 levels) each as within-subject factors. It is possible that, despite our attempt to control for individual differences in arithmetic ability, factors such as age or facility with mental calculation might have a systematic effect on our data pattern. Therefore, age and adding span were entered into the analysis as covariates so as to control for any effects of these variables.
Results of the analysis showed that there was an overall difference in the numbers of errors produced by the four subject groups $[F(3,18)=6.87, p<.01]$. There was also a highly significant disruption under dual-task conditions, with a mean of 4.5 errors (22.5\%) compared with performing mental addition on its own $(M=2.4 \mathrm{er}$ rors; $12 \%)[F(1,18)=59.68, p<.001]$. The number of carries also had a substantial effect, with a mean for single-carry problems of 2.5 errors $(12.5 \%)$ and a mean for multiple-carry problems of 4.4 errors $(22 \%)$ $[F(1,18)=34.36, p<.001]$. The number of carries did not interact with group $[F(1,18)=1.54, p>.2]$ or with single versus dual task $(F<1)$. Finally, whether addition was performed alone or with a secondary task interacted with the group variable $[F(3,18)=16.34, p<$ $.001]$. Mean data for each group under single- and dualtask conditions are shown in Table 2, from which it appears that random generation produces a much larger disruption in performance than do the other secondary tasks. Post hoc pairwise comparisons were carried out on the means for this interaction using Newman-Keuls tests, revealing that only articulatory suppression $(p<$ $.01)$ and random generation $(p<.001)$ resulted in significantly poorer performance.

Despite our attempts to control for adding span and age, it is possible that other sources of intersubject variability in the scores obtained from our relatively small sample of subjects could result in systematic differences between the groups. One way to reduce the influence of intersubject variability in mean scores is to analyze the differences between conditions for each subject. For this, we derived a single difference score for each subject by subtracting the single-task error score from the dual-task error score. We also had a priori expectations about the relative effects of each of the secondary tasks. A model that implicated subvocal rehearsal and general executive resources in mental arithmetic would predict that random generation would result in a larger difference between single- and dual-task performance across subjects than would articulatory suppression, and this in

Table 2

Mean Number and Percent of Addition Errors With Auditory and Visual Presentation of Numbers for Four Groups of Subjects in a Single-Task Controł Condition and With Irrelevant Pictures, Hand Movement, Articulatory Suppression, Random Generation, and Irrelevant Speech

\begin{tabular}{|c|c|c|c|c|}
\hline & \multicolumn{4}{|c|}{ Task } \\
\hline & \multicolumn{2}{|c|}{ Single } & \multicolumn{2}{|c|}{ Dual } \\
\hline & $M$ & $\%$ & $M$ & $\%$ \\
\hline \multicolumn{5}{|c|}{ Auditory Presentation } \\
\hline Pictures & 2.3 & 11.5 & 2.42 & 12.1 \\
\hline Movement & 3.0 & 15.0 & 3.75 & 18.8 \\
\hline Articulatory suppression & 1.6 & 8.0 & 4.1 & 20.5 \\
\hline Random generation & 2.8 & 14.0 & 7.7 & 38.5 \\
\hline \multicolumn{5}{|c|}{ Visual Presentation } \\
\hline Speech & 1.3 & 6.5 & 2.8 & 14 \\
\hline Movement & 1.6 & 8.0 & 3.0 & 15.0 \\
\hline Articulatory suppression & 1.3 & 6.5 & 2.8 & 14 \\
\hline Random generation & 0.7 & 3.5 & 8.8 & 44 \\
\hline
\end{tabular}


turn would yield larger dual-task decrements than would either irrelevant pictures or concurrent tapping. Using a priori contrasts, these expectations were confirmed, with significant contrasts between random generation and articulatory suppression $[F(1,18)=10.76, p<$ $.005]$ and between articulatory suppression and the combined effects of movement and irrelevant pictures $[F(1,18)=13.06, p<.005]$. All subjects in the movement, articulatory suppression, and random-generation groups committed more errors under dual-task conditions. Only 2 of the 6 subjects in the pictures condition showed poorer performance under dual-task conditions.

In our earlier studies on counting (Logie \& Baddeley, 1987), we found it fruitful to analyze error magnitude as well as the number of errors, and we turned next to the analyses of these data from our present experiment. Error magnitude was calculated as a percentage of the correct total as follows:

$\%$ Error Size $=\frac{\text { Modulus }(\text { Subject Response }- \text { Correct Total })}{\text { Correct Total }} \times 100$.

By using the modulus, all negative scores were converted to positive values.

Data from all 24 subjects were entered into an ANOVA identical to that used for number of errors. As before, age and adding span were entered as covariates. The analyses showed a marginal difference among the four groups in the overall mean error magnitudes $[F(3,18)=3.03, p<.06]$. There was a main effect of performing a secondary task $[F(1,18)=19.06, p<$ .001 ] and an effect of number of carries [mean single carry $=2.81 \%$; mean multiple carries $=4.23 \%$; $F(1,18)=5.70, p<.05]$. There was an interaction between group and single versus dual task $[F(3,18)=4.26$, $p<.025]$; the means for this interaction are shown in Table 3. Number of carries did not interact with group $(F<1)$ or with single/dual task $[F(1,18)=1.75$, $p>$.2]. The three-way interaction was not significant $(F<1)$. Post hoc comparisons on the group $\times$ single/ dual task interaction showed that only random generation produced a significant increase in error magnitude $(p<.001)$, with a marginal effect of articulatory suppression $(p=.073)$. The effects of movement and pictures were nonsignificant.

Again, we carried out paired contrasts on the dualtask-single-task difference scores, which revealed that random generation produced larger dual-task decrements than did pictures and movement combined $[F(1,18)=13.40, p<.01]$, but the contrast between random generation and articulatory suppression was marginal $[F(1,18)=3.47, .05<p<.1]$, and the contrast between articulatory suppression and the combined effects of pictures and movement was not significant $[F(1,18)=2.22, p>.1]$. Looking at the performance of individual subjects, all subjects in the random-generation and articulatory suppression groups showed larger error magnitude scores under dual-task conditions. In the pictures condition, 5 of 6 subjects showed poorer dual-task
Table 3

Mean Percentage Error Magnitude of Addition Errors With Auditory and Visual Presentation of Numbers for Four Groups of Subjects in a Single-Task Control Condition and With Irrelevant Pictures, Hand Movement, Articulatory Suppression, Random Generation, and Irrelevant Speech

\begin{tabular}{lll}
\hline & \multicolumn{2}{c}{ Task } \\
\cline { 2 - 3 } & Single & Dual \\
\hline
\end{tabular}

Auditory Presentation

$\begin{array}{lcc}\text { Pictures } & 2.7 & 3.7 \\ \text { Movement } & 1.0 & 1.7 \\ \text { Articulation suppression } & 2.2 & 5.7 \\ \text { Random generation } & 2.1 & 9.0 \\ & \text { Visual Presentation } \\ \text { Speech } & 1.0 & \\ \text { Movement } & 0.8 & 1.8 \\ \text { Articulation suppression } & 0.8 & 1.7 \\ \text { Random generation } & 0.4 & 2.1 \\ \end{array}$

performance; in the movement condition, 4 of the 6 subjects showed poorer dual-task performance.

In each of our analyses, we examined the data pattern while covarying out the influence of age and adding span. To evaluate whether age difference or adding span scores might account for some of the variability in this experiment, we calculated the correlations between age, adding span, and the dual-task-single-task difference scores across all 24 subjects, both for error number and for proportional error magnitude. There were no significant correlations between any of these variables, most notably between age and dual-task interference (for error number, $r=-.02$; for error magnitude, $r=-.09$ ) and between adding span and dual-task interference (for error number, $r=.07$; for error magnitude, $r=-.25$ ). Finally, age and adding span were unrelated $(r=.07)$.

Secondary task performance. We next turned to an analysis of performance on the secondary tasks. With irrelevant pictures, there was no measure of performance; therefore, we concentrated on data for hand movement, articulatory suppression, and random generation.

For the movement task, we used the mean interresponse times as our measure of performance. Thus, for each subject in the movement control condition, we calculated the mean interpress interval for each of the 10 25 -sec periods, ignoring the intervals for the first $3 \mathrm{sec}$ and for the last $2 \mathrm{sec}$ in each period. In the dual-task condition, we calculated the mean interpress interval for each of the first 10 trials, ignoring for each trial the first $3 \mathrm{sec}$ prior to onset of the number sequence. We used mean interpress intervals from each trial rather than raw data in the analysis because the number of keypresses on each trial varied depending on the actual rate achieved by the subjects. For each of the 6 subjects in this group, this gave us 10 data points for control (single task) movement and 10 data points for trials when movement was performed concurrently with mental addition. An ANOVA on these data showed that there was no significant difference $[F(1,54)=1.52, p>.2]$ in the intertap 
intervals for the single-task condition $(M=1,559 \mathrm{msec})$ or the dual-task condition $(M=1,611 \mathrm{msec})$.

We carried out a similar analysis on the interresponse interval data for articulatory suppression. For the 6 subjects in this group, there was a highly significant difference $[F(1,54)=60.93, p<.001]$ between the singletask condition $(M=1,249 \mathrm{msec})$ and the dual-task condition ( $M=1,817 \mathrm{msec})$.

Turning to random generation, we had available data on interresponse times and in addition we tape-recorded the actual responses produced by each subject. Our intention in collecting these latter data was to analyze the effect of dual-task demands on degree of randomness of the responses. This analysis requires an equal number of responses in each of the two conditions to be compared; however, 4 of the 6 subjects in this group produced fewer than 10 responses on 34 of the 80 dual-task trials for these subjects. On 10 of these 34 trials, fewer than six responses were generated, and on one of these trials, 1 subject produced no responses at all. The 4 subjects who failed to produce sufficient responses had adding spans of $4,5,4$, and 3 . The 2 subjects who produced sufficient responses had adding spans of 4 and 5 . Therefore, there was no tendency for a failure to produce randomly generated responses under dual-task conditions to be associated with a low adding span. In contrast, all of our subjects successfully performed the random-generation task on its own. Across all subjects, there were significantly fewer responses $(t=7.16, p<.001)$ generated under dual-task conditions $(M=13.47, S D=2.97)$ than under single-task conditions $(M=19.25, S D=5.88)$.

These observations on their own attest to the size of the disruption when combining random generation with mental arithmetic. However, we were also able to carry out a one-way ANOVA on the data that were available for interresponse times. This supported the conclusion that dual-task performance was highly disruptive $[F(1,40)=43.66, p<.001]$, with a single-task mean of $1,184 \mathrm{msec}$ and a dual-task mean of $1,539 \mathrm{msec}$.

\section{Discussion}

Random generation produced very substantial error scores in both number and magnitude. Articulatory suppression produced a smaller degree of disruption, but mental addition was largely unimpaired by hand movement or presentation of irrelevant pictures. The disruptive effects of random generation and articulatory suppression clearly were not due to a tradeoff in performance between the primary and secondary tasks. Interresponse intervals for articulatory suppression and random generation were significantly slower under dual-task conditions, suggesting that performance on these tasks was also disrupted when coupled with mental addition. Moreover, the lack of a disruptive effect on mental arithmetic of the hand movement task was matched by a similar lack of disruption of hand movement by concurrent arithmetic.

The data arising from the use of articulatory suppression are highly consistent with a role for subvocalization in mental arithmetic and are in line with the data obtained in our previous experiments on counting. The large disruption of performance associated with random generation is particularly striking, supporting the view that the cognitive mechanisms that underlie mental addition are also pivotal to oral generation of random letter sequences. In view of our interpretation of random generation as a task that reflects the operation of the central executive system in working memory, these data are consistent with the suggestion that mental arithmetic as studied here also relies on central executive resources. In contrast, the lack of any disruptive effect of concurrent hand movement or irrelevant pictures is not consistent with a role for visual or spatial imagery in this form of mental addition.

Of additional interest is that, although the disruptive effects on error number were quite substantial, the effect on error magnitude was rather small. In other words, although subjects make more calculation errors when carrying out random generation or articulatory suppression, the response they give is quite close to the correct total. This mirrors a finding in our previous experiments on counting and is consistent with the idea that components of working memory may be involved in maintaining accuracy in arithmetic but that, even when working memory is occupied, subjects still have available to them some means of producing a reasonable estimate of the correct total. We shall return to this point in the final discussion.

While the pattern of data maps well onto our hypothesized roles for working memory in mental arithmetic, it is important to consider alternative interpretations of these data. One possibility is that the differences in the levels of disruption associated with each of the secondary tasks could arise from the relative levels of difficulty of these tasks. This view is difficult to sustain, since there are no a priori reasons to suggest that, for example, the hand movement task would be any less or any more difficult than articulatory suppression. However, the general issue of task difficulty is a topic that we shall consider in more depth in the final discussion.

Another possible objection to the working-memory hypothesis is that the pattern of data obtained may be due to the modality of input. That is, auditory presentation of the numbers for adding clearly requires the use of an auditory verbal input system. Thus, one possible alternative interpretation for our results is that articulatory suppression and random generation may somehow be interfering with the initial encoding of the numbers and that the processes required for calculation do not rely on our hypothesized components of working memory. Therefore, in Experiment 2, we examined the effects of these secondary tasks when the numbers for addition were presented visually rather than auditorily. If this interpretation is correct, we should find that the disruptive effects of articulatory suppression and random generation would be removed. We should also find that the overall error rates and error magnitude levels on the 
arithmetic test under single-task conditions would be more or less the same as for auditory presentation.

The working-memory hypothesis predicts a contrasting outcome from a switch to the visual input modality. Specifically, the model of the articulatory loop as described in the introduction serves as an input buffer for speech as well as a temporary storage system for verbal material. Thus, if the processes involved in calculation do rely at least in part on the articulatory loop in working memory, we might expect that requiring subjects to listen to the numbers that they have to add up would involve the articulatory loop as an input buffer and therefore would interfere with the role that the articulatory loop serves in accurate mental addition. As a consequence, visual presentation of the numbers for addition should reduce the load on the articulatory loop as an input buffer, allowing it more easily to serve its function in calculation. From this, we would predict that overall levels of arithmetic performance should be better with visual presentation. We would also predict that articulatory suppression should produce a smaller, but significant, disruptive effect.

The argument that we have outlined for articulatory suppression could in principle also be applied to random generation. Random generation could be seen as a more complicated form of articulatory suppression in which the subject has to produce a series of different utterances rather than repeating the same word throughout. It could be this involvement of the speech system, instead of general-purpose executive resources, that account for the role of random generation in these tasks. If this turns out to be an adequate explanation for the effects of random generation in these experiments, we should find that the disruptive effects of this task, like the disruptive effects of articulatory suppression, will disappear with visually presented numbers for addition. In contrast, the hypothesis that links random generation and key aspects of arithmetic with functioning of a central executive would predict a replication in Experiment 2 of the substantial mutual disruption associated with the use of random generation in Experiment 1.

An additional motivation for changing the modality of input was to further investigate the very modest interference by irrelevant speech obtained in our previous experiments with counting (Logie \& Baddeley, 1987). Clearly, it would have been impractical in Experiment 1 to couple the auditory presentation of irrelevant speech with auditory presentation of the numbers for adding. For similar reasons, it would not be practical to couple visual presentation of numbers for addition with the visual presentation of irrelevant pictures, and this latter condition was omitted from Experiment 2.

Finally, for the same reasons that we might expect auditory input to interfere with some of the processing and storage involved in mental arithmetic, it will be interesting to discover whether visual presentation will result in demands being placed on visuospatial processing or storage. That is, although we did not get significant disruption from concurrent hand movement with auditory presentation of numbers, the requirement to encode visually presented input may well place demands on visuospatial working memory arising from its function as a visuospatial input buffer. As such, it is possible that hand movement will result in some disruption of the subject's ability to encode and calculate sums from visually presented numbers.

\section{EXPERIMENT 2 Mental Arithmetic With Visual Presentation}

\section{Method}

Subjects. A total of 24 subjects participated in this experiment (13 females and 11 males). All were members of the Psychology Department Volunteer Subject Panel comprising members of the general public. Their ages ranged from 29 to 66 years, with a mean of 47 years.

Arithmetic task. The procedure was essentially the same as that for Experiment 1, except that the numbers for adding were presented one at a time in the center of a computer screen. Each number appeared for $1 \mathrm{sec}$, with warning beeps and the timings between numbers identical to those shown in Table 1 for Experiment 1 . As before, each subject's arithmetic span was measured first; this served as the basis for the length of the number sequences used for each subject in the main experiment. The numbers of subjects for each sequence length are shown in Table 1. When each sequence was completed, three question marks appeared in the center of the screen, indicating that the subject was to respond orally with the calculated total.

Secondary tasks. Three of the secondary tasks were identical to those used in Experiment 1-namely, hand movement, articulatory suppression, and random generation of letters--with performance recorded for each secondary task performed alone as well as when combined with the arithmetic task. The fourth secondary task involved presenting through headphones, spoken at a one per second rate, a series of two-digit numbers, which the subjects were instructed to ignore as much as possible. There was no attempt to synchronize the presentation of the spoken numbers with the visual presentation of the numbers for addition. On each trial, the tape recording of "unattended speech" was started before commencing presentation of the numbers for addition and stopped after the last item was shown on the screen. The choice of twodigit numbers rather than other forms of speech stemmed from the fact that our previous studies have shown little or no interference from unattended speech on simple counting tasks (Logie \& Baddeley, 1987), even when the heard material consisted of taperecorded random numbers. We wished to maximize the sensitivity of the procedures to any interference that might ensue. That is, if no interference effect were to be obtained, it would then be difficult to criticize our procedures on the grounds that they lacked sensitivity with respect to the variables under study.

\section{Results}

Performance on mental addition. As for Experiment 1 , we first analyzed the number of incorrect totals for each of the four subject groups, within groups for single- and dual-task performance, and for single- and multiple-carry problems. As for Experiment 1, age and adding span were included as covariates.

The ANOVA showed that there was an overall difference in the numbers of errors produced by the four groups $[F(3,18)=28.10, p<.001]$ and a significant overall disruptive effect of performing a secondary task $[F(1,18)=581.90, p<.001]$. There was also a main ef- 
fect of number of carries in problems $[F(1,18)=33.08]$, with a mean of 1.9 errors for single-carry problems and a mean of 3.7 for multiple-carry problems. The number of carries did not interact with the subject group $[F(3,18)=1.01, p>.1]$ or with single versus dual task $[F(1,18)=2.66, p>.1]$. There was a highly significant interaction between group and single versus dual task $[F(3,18)=168.31, p<.001]$; mean data for this interaction are shown in Table 2. Post hoc comparisons using Newman-Keuls tests revealed that all four of the secondary tasks produced a significant disruption in adding performance (in all cases, $p<.001$ ). However, it appears from Table 2 that the disruption associated with random generation was much larger than that for the other three secondary tasks. The three-way interaction of problem demand, single/dual task, and group was not significant $[F(3,20)<1]$.

As in Experiment 1, we tested our predictions about the relative effects of the different secondary tasks by means of a priori contrasts on the dual-task-single-task difference scores. Random generation produced significantly larger dual-task decrements than did articulatory suppression $[F(1,18)=337.40, p<.001]$, arm movement $[F(1,18)=269.97, p<.001]$, or presented speech $[F(1,18)=345.48, p<.001]$. The size of the dual-task decrements produced by the latter three secondary tasks did not differ from one another.

A similar analysis was carried out on the percentage error magnitude data. As for the number of errors, there was a significant difference in the size of the errors produced by the four different subject groups $[F(3,18)=$ $37.84, p<.001]$, an overall disruptive effect of dual-task performance $[F(1,18)=90.20, p<.001]$, and an interaction between group and dual task $[F(3,18)=48.17$, $p<.001]$. The mean data for this interaction are shown in Table 3. Post hoc pairwise comparisons using Newman-Keuls tests revealed that random generation was the only secondary task that significantly increased error magnitude $(p<.001)$. None of the other secondary tasks showed a significant disruptive effect (in all cases, $p>.4$ ). Finally, the multiple-carry problems $(M=3.30 \%)$ produced larger errors overall than did the single-carry problems $(M=1.94 \%)[F(1,18)=20.78$, $p<.001$ ]. Carries did not interact with group $(F<1)$ or with single versus dual task $[F(1,18)=2.91, p>.1]$, and the three-way interaction was not significant $(F<1)$.

Planned comparisons on the dual-task-single-task difference scores revealed that random generation produced larger dual-task decrements in performance than did articulatory suppression $[F(1,18)=99.86, p<$ $.001]$, movement $[F(1,18)=102.20, p<.001]$, or presented speech $[F(1,18)=112.71, p<.001]$. The effects of the last three secondary tasks did not differ from one another.

As for Experiment 1, we examined the possible relationship between age, adding span, and sensitivity to dual-task interference. Age did not correlate with dualtask-single-task difference scores for error number $(r=$
$-.12)$ or error magnitude $(r=-.01)$. Similarly, adding span did not correlate with dual-task interference for error number $(r=-.11)$ or error magnitude $(r=-.09)$. Finally, age and adding span did not correlate with one another $(r=-.16)$.

Secondary task performance. Next, we analyzed the secondary task performance, following the procedure for analysis used with the data from Experiment 1 . The subjects had slower interresponse intervals for articulatory suppression under dual-task conditions $(M=$ $1,183 \mathrm{msec})$ than when they performed suppression on its own $(M=1,108 \mathrm{msec})[F(1,54)=34.91, p<.001]$. Although the absolute size of the effect was quite small, it was shown by all subjects in this group. The rate of hand movement did not change significantly between single- and dual-task conditions $[F(1,54)<1]$, with a mean interresponse interval for single-task movement of $999 \mathrm{msec}$ compared with a mean of $984 \mathrm{msec}$ when hand movement was combined with concurrent arithmetic. Random-generation interresponse intervals differed significantly between single-task conditions $(M=$ $1,151 \mathrm{msec})$ and dual-task conditions $(M=2,379 \mathrm{msec})$ $[F(1,54)=233.17, p<.001]$; this was shown by all subjects in this group.

Five out of the 6 subjects in the random-generation group were able to produce an adequate number of randomly generated responses, allowing for a comparison of randomness between single- and dual-task performance. For this comparison, we used the Evans RNG index (Evans, 1978). This index strictly measures the amount of redundancy in the response, so that a higher index indicates more redundancy and less randomness. Since the indices are derived from different numbers of responses for each subject, and so few subjects are involved, it is not appropriate to carry out a formal statistical analysis on these data. The relevant indices for each of the 5 subjects are shown in Table 4, from which it is clear that all 5 subjects showed a higher index of redundancy under dual-task conditions than when random generation was performed as a single task.

We were also interested in the extent to which the overall levels of performance in this experiment matched those found for auditory presentation in Experiment 1 . For this, we examined just the control (single task) levels of performance for addition in Experiments 1 and 2, again including age and adding span as

Table 4

Index of Degree of Redundancy (Evans, 1978) for 5 Subjects When Randomly Generating Letters Alone (Single Task) or When Concurrently Performing Mental Arithmetic With Visual Presentation (Adding)

\begin{tabular}{ccc}
\hline Subject Number & Single Task & Adding \\
\hline 19 & .2025 & .4643 \\
20 & .0871 & .2514 \\
21 & .1118 & .1329 \\
22 & .0791 & .1821 \\
23 & .0790 & .1140 \\
\hline
\end{tabular}


covariates. There was a significant difference in the number of errors produced in the two experiments $[F(1,38)$ $=12.48, p<.002]$, with a mean of $2.42(12.1 \%)$ errors for auditory presentation and a mean of $1.23(6.2 \%)$ errors for visual presentation. The same result was found for error magnitude $[F(1,38)=9.13, p<.005]$, with a mean for auditory presentation of $2.02 \%$ and a mean for visual presentation of $0.74 \%$. In neither case did the difference between auditory and visual presentation interact with the four subject groups in each experiment.

Finally, although age and adding span did not correlate with the size of dual-task disruption in either Experiment 1 or Experiment 2, we thought it would be worthwhile to look at the correlation between adding span and overall levels of arithmetic performance across both experiments. Age did not correlate with single- or dual-task performance. However, adding span did correlate significantly with the number of errors observed in the control conditions for the single-carry problems $(r=-.41, n=48, p<.05)$ and the multiple-carry problems $(r=-.42, n=48, p<.05)$. Adding span did not correlate with dual-task performance when performance was measured by error frequency or error magnitude.

\section{Discussion}

The motivation for Experiment 2 was threefold. First, we wished to see whether the disruptive effects of articulatory suppression and random generation that we found for auditory presentation in Experiment 1 also would appear with visual presentation. Second, we wanted to determine whether or not unattended speech would disrupt mental arithmetic. Finally, we were interested in whether overall levels of performance differed between the two experiments.

With respect to the first of these, the results evidently support the view that articulatory suppression has a significant disruptive effect on mental arithmetic, even with visual presentation of the numbers. This was shown in the number of errors in arithmetic and in performance on the suppression task itself, although there was no effect on error magnitude. What is notable, however, is that the disruptive effect of articulatory suppression was much reduced in Experiment 2, relative to the disruption shown in Experiment 1. This supports the view expressed above that at least some of the interference shown in Experiment 1 arose from disruption of auditory input. Nevertheless, the level of disruption shown in Experiment 2 is sufficient to argue that subvocal rehearsal is indeed required for mental arithmetic, independently of the modality of input. Random generation produced a substantial disruptive effect on performance that was much greater than that shown by any of the other secondary tasks, and this disruption was reflected in an increased error rate and an increase in the size of the errors made under dual-task conditions. The appearance of these interference effects in Experiment 2 supports the view that working memory is involved in the arithmetic task, and not merely in the initial encoding of the number stimuli.

With respect to the second motivation for this study, it is notable that we did obtain a small increase in the number of errors when arithmetic was coupled with presentation of a tape of words that were to be ignored. The effect is by no means dramatic, but it is at a level that is not statistically distinguishable from the effect of articulatory suppression. What is somewhat surprising is that it did not produce a much larger disruption of performance, given that these "unattended" words themselves were in the form of two-digit numbers. This is consistent with the view that the source of the interference was at the level of phonological or articulatory processing of the numbers rather than at a more abstract semantic level.

The small interference effects found for hand movement with visually presented numbers for adding is consistent with a role for the visuospatial component of working memory in this form of the addition task. Clearly, with visual presentation, subjects have the opportunity to retain the numbers in the form of visual codes. It is also open to them to translate the visually presented information into some other form, such as a phonological or articulatory code for temporary storage. We referred in the introduction to the possibility that subjects can perform mental arithmetic in a variety of ways and that they are not necessarily restricted to one particular strategy. That is, visual coding of the numbers is one possible strategy that is available to them. Likewise, the suggestions by Moyer and Landauer (1967) and Dehaene (1992) that subjects can use an image of a "number line" to assist mental arithmetic is entirely consistent with our data. However, our data also suggest that visual imagery is probably not used spontaneously when the materials for the calculation are presented auditorily.

Despite these dual-task impairments, it was also interesting to note that the overall error rate and error magnitude were much smaller than those shown in Experiment 1. From Tables 2 and 3, the absolute size of the dual-task disruption appeared to be smaller in Experiment 2 . An alternative measure of the difference in performance between the two experiments might have been to use the mean arithmetic span that was determined for each subject. However, the adding-span scores shown in Table 1 for the subjects in each experiment do not differ statistically, suggesting that the subjects in the two experiments were roughly matched for arithmetic ability. In any case, any differences between experiments on this measure could have been attributed to chance differences in the samples of subjects who took part. Thus, despite the fact that the demands of the addition tasks were adjusted for each subject's competence with mental addition in both experiments, the subjects were better able to cope with the arithmetic task under both single-task and dual-task conditions when input was visual. This pattern of results is consistent with the view that some of the interference found in Experiment 1 arose from the 
modality of input of the numbers for addition, but it is equally clear that not all of the interference can be attributed to this source.

\section{GENERAL DISCUSSION}

Our original aim in conducting these experiments was to investigate whether the everyday task of mental addition would be amenable to an analysis within the framework of working memory. With the use of dual tasks, it appears that just such an analysis is informative, and the data we have obtained are consistent with the relatively unexplored assumption that working memory has a role in this task. Furthermore, the differential nature of the disruption associated with each of the secondary tasks employed indicates differential loading on the various components of working memory.

We briefly discussed earlier the possibility that the differential disruptive effects of our secondary tasks could be tackled by reference to the relative difficulty of the secondary tasks. In part, we have answered that challenge by questioning whether we might be able to determine independently of our reported data which of, for example, articulatory suppression or hand movement is the more difficult task. A number of previous studies have shown that hand movement in the form used here disrupts performance of visuospatial tasks under circumstances in which articulatory suppression does not, whereas the converse is the case for verbal short-term storage tasks (e.g., Farmer et al., 1986). In sum, it is the nature, rather than the difficulty, of the tasks which is crucial. Task difficulty could also be explored in discussing the effects of random generation. However, invoking the concept of task difficulty in itself begs a number of questions as to what it is about the task that makes it difficult. For example, task requirements may be thought to be difficult because they make demands on shared cognitive resources. Moreover, subjective estimates of the difficulty of two tasks when performed on their own turn out to be poor predictors of how well subjects perform when the two tasks are performed concurrently (e.g., Logie et al., 1989; Wickens \& Weingartner, 1985; Yeh \& Wickens, 1988). The concept of task difficulty risks the danger of circularity in that it can be defined only in terms of task performance, and it turns out not to be a very useful explanatory construct.

A further objection to our claims might arise from the use of subjects from the general population who vary widely in age. Such a sample clearly is not as homogeneous as the more frequently used samples of college students, and we may pay the penalty that our procedures are not sufficiently sensitive to the phenomena of interest. However, there is a significant advantage to using less homogenous samples in that it gives us much greater confidence as to the generality of our findings. Any phenomena that arise from the data derived from such groups are likely to reflect the cognitive processes of a much larger range of the population, rather than the specific educational experience of college students within a narrow age band. Moreover, given the lack of significant correlations between age, adding span, and dualtask disruption, our findings cannot readily be explained in terms of chronological age or individual differences in ability with mental arithmetic.

One intriguing aspect of the data stems from our manipulation of "task demand"- namely, the number of carries in each of the addition problems. There was clearly an overall effect of task demand manipulated in this way, but the effect of number of carries was not enhanced under dual-task conditions in either experiment. This may simply be because the variability in task demand between the two problem types was insufficient, or that the subject samples were too small and were drawn from a wide age range. However, we believe that these are unlikely explanations since the problem types show a main effect of number of carries, and the subject samples allowed sufficient sensitivity to show up differential effects of our secondary tasks on both problem types. A more likely account is that the processing demands of number of carries may rely on part of the cognitive system that was not required for performing any of the secondary tasks. That is, the system required for keeping track of carries is not necessarily the same system that maintains accuracy in calculation (see discussion below). One possibility is that keeping track of carries relies on some form of rule-based procedure. Another possibility is that the load on working memory of keeping track of a single carry at any one time is not sufficient to be sensitive to dual-task interference. Of course, the lack of an interaction may stem from a more mundane procedural factor, such as the use of mixed rather than blocked presentation of the different problem types. However, our intuition is that a blocked design would reduce the effects of problem demand because subjects could develop strategies to deal with the consistent problem types in a given set of trials. Clearly, the issue of how carries are handled is well worth exploring in future studies using larger subject samples and a wider range of problem types.

A more straightforward aspect of the data pattern arose from the dual-task manipulations and replicated one of the findings that we reported in our earlier experiments on counting (Logie \& Baddeley, 1987). Specifically, although both articulatory suppression and random generation produced a significant increase in the number of errors observed, these incorrect responses tended to be very close to the correct total. Even with concurrent random generation, the size of the error was relatively modest and, in the group averages, was within $10 \%$ to $12 \%$ of the correct total.

This leads to the suggestion that working memory does have a role to play in addition, and that subjects have available to them strategies that allow respectable levels of performance even when working memory is otherwise occupied. One possible way to account for this is to return to the idea that there are at least two compo- 
nents of counting and arithmetic tasks: one that maintains accuracy and is prone to interference from random generation and articulatory suppression, and one that allows for reasonable guesses even under dual-task conditions. From our earlier review of the literature, it was clear that subjects appear to have access to a vocabulary of sums and totals or arithmetic facts that they can access relatively automatically (Campbell \& Graham, 1985; Dehaene, 1992; Sokol et al., 1991). Automated retrieval of arithmetic facts would allow accurate answers to a range of sums depending on the arithmetic vocabularies of the subjects involved. Moreover, access to such a knowledge base would allow approximations where the exact total was not immediately available. Thus, for example, given the sum of $28+19$, most subjects would recognize that this was very close to $30+20$, the answer to which would be readily available. Subjects might also notice that both numbers are a little less than 20 and 30 , so that the correct answer would be a little bit less than 50 . They could then guess 46,47 , or 48 , and be assured of being very close to the correct total. Indeed, they have a reasonable chance of being correct. All of this could occur with only a very limited reliance on a system that was concerned primarily with ensuring accuracy.

This leaves us with a requirement to account for the additional interference obtained from random generation. Our interpretation handles this very readily by suggesting that random generation interferes in part with the same processes that are disrupted by articulatory suppression - namely, maintenance of accuracy - but that it places demands also on the system that carries out calculations and strategies for estimation. That is, subvocal articulation assists retention of accurate running totals, but a more general-purpose executive resource is involved in implementing the calculation procedures or estimation strategies when these are required. The observation that, on some dual-task trials (especially in Experiment 1), several of our subjects simply stopped generating items at random to allow them to perform the mental arithmetic task lends strong support to this interpretation.

This interpretation fits with data collected elsewhere. For example, Dehaene and Cohen (1991) have reported a brain-damaged patient with a severe impairment in calculation. However, the impairment appears to be restricted to accuracy, since the patient can perform approximate calculations satisfactorily. For example, when asked whether $2+2=5$, the patient is likely to say "yes." However, the patient rarely makes a mistake when asked whether $2+2=9$. Dehaene and Cohen interpret these data as suggesting that there are two mechanisms in calculation: one dealing with accuracy, the other with approximation. It is interesting to note that their patient also appears to have a fairly severe verbal short-term memory deficit, which fits well with our hypothesis that the articulatory loop system provides some of the functions for maintaining accuracy by means of subvocal re- hearsal. It also fits with Widaman et al.'s (1989) suggestion that accuracy in calculation involves a relatively slow, implicit speech process.

Further support is derived from theoretical developments in studies of mathematical reasoning carried out from a very different perspective by Brainerd and his colleagues (e.g., Reyna \& Brainerd, 1993). Reyna and Brainerd present an account of the problem-solving and reasoning processes involved in mathematics by suggesting that there are essentially two forms of reasoning: quantitative (linked with numerical accuracy) and gistbased or "fuzzy" reasoning. They have argued that fuzzy reasoning is the form that would be adopted naturally by adults and that develops naturally in children. Thus, in most cases in everyday life, we use concepts like more, less, longer, and shorter, or more fine grained versions such as a little more or a bit shorter. Rarely, they argue, are we required to specify an exact quantity. Reyna and Brainerd maintain that this natural form of reasoning is in stark contrast with the common approach taken to teaching mathematics, which tends to emphasize accuracy. This in turn may lead to widespread difficulties in mathematics encountered both in the classroom and in everyday adult life. For example, when calculating the price of our chosen purchases in the supermarket, normally we would be interested in whether the bill came to around $£ 30$ or around $£ 100$ but would be less concerned about the whether the exact total came to $£ 30.28$ or $£ 29.56$. The concept of fuzzy reasoning in Reyna and Brainerd's terms does make intuitive sense and is consistent with our own thesis that approximate calculations are carried out by mechanisms that are at least partly independent of those systems required for accuracy. Whether or not fuzzy reasoning is the more natural form of reasoning is a moot point. Accuracy often is also important, and although we may work in ball-park figures when filling our shopping cart, it is important to get the numbers correct when it comes to writing the check.

Our data fit less readily with the model developed by McCloskey and his colleagues (e.g., McCloskey, 1992; McCloskey et al., 1991; Sokol et al., 1991), who argue that mental arithmetic involves operations carried out on relatively abstract representations of numbers and number facts and that this occurs independently of the modality or form of input or output. At least one approach to this apparent disagreement would be to refer to differences in the experimental procedures used. For example, one difference between our experiments and a number of other studies is that it is common in this area of research to use verification paradigms where subjects are given an answer along with the sum and are asked whether or not the given answer is correct. This approach has the advantage of allowing the collection of response times as well as accuracy scores. Even in studies where a numerical response is required (e.g., Sokol et al., 1991), it is common to present subjects with a series of single sums with a response required for each one. A feature of our procedures is that not only do sub- 
jects have to respond with a total, they also have to keep in mind a series of running totals to which they add the next presented item. This procedure probably places greater demands on working memory than do individual sums. Furthermore, when more than two numbers are presented in a sequence, subjects may not have within their vocabulary of sums the answers to the third, fourth, or fifth addition in the sequence. For example, subjects may represent as an arithmetic fact the sum $18+17=35$, but they are less likely to have a specific representation of $35+18=53$ or of $53+29=82$. These kinds of demands on the cognitive system probably represent a very common requirement for arithmetic in everyday life (e.g., adding up the prices of a series of purchases). Whether the components of working memory and subvocal rehearsal in particular are required for single sums would be an interesting topic to explore.

In a recent paper, Ashcraft et al. (1992) have argued that working-memory resources are indeed required for single sums in verification paradigms. In one of their experiments, they also used dual-task procedures, although they did not select their dual tasks so as to involve different components of working memory, nor did they formally record performance on the secondary tasks. Ashcraft et al. concluded that even for relatively simple arithmetic, access to arithmetic facts and their manipulation are not entirely automatic and probably rely on working-memory resources.

One comment raised by a reviewer of an earlier draft of this paper was that working memory might be involved only under dual-task conditions. That is, working memory might be required to coordinate the performance of two simultaneous tasks but not be essential to the performance of mental arithmetic when performed alone. We believe this is unlikely for the following reasons. First, this interpretation rests on the assumption that working memory comprises a single flexible system for processing and storage, which would have a coordinating role in dual-task performance. We have argued that working memory is better thought of as a set of components that act in concert in various combinations according to task demands. Only one of these components, the central executive, would serve a coordinating role. There is a considerable body of evidence for such a multicomponent system based on data from normal adults, neuropsychological patients, and children (e.g., Baddeley, 1986, 1992; Logie, 1993). A second reason why the dual-task coordination hypothesis is unlikely is that not all of our secondary tasks result in interference. Of course, it could be argued that only some dual-tasks conditions result in demands on a coordinating function, but all of these tasks have been shown to interfere with different primary tasks and their tendency to interfere depends on the task with which they are combined rather than the inherent difficulty of the task itself. This view then boils down to the task-difficulty interpretation, which, as we have argued above, is not a very useful approach. Finally, of course, as we discussed in the intro- duction, we are not alone in suggesting that mental arithmetic draws on working-memory resources.

The extent to which working memory is shown to be crucial in arithmetic may also depend on the nature of the working-memory system envisaged. As noted earlier, our own view is of a multicomponent system; some authors view working memory as a single flexible system providing temporary storage, processing resources, and the allocation of attention (e.g., Engle, Cantor, \& Carullo, 1992; Geary \& Widaman, 1992; Just \& Carpenter, 1992). This latter form of working memory appears to correspond roughly to the central executive component in the Baddeley and Hitch (1974; Baddeley, 1986) model of working memory. In a study of individual differences, Geary and Widaman (1992) have suggested that the measure of working memory used in their studies is related to arithmetic performance. This is entirely consistent with our own view that the central executive component of working memory serves an important function in these tasks. We should be cautious, however, about drawing close parallels between the Geary and Widaman data and our own, since the nature of the arithmetic tasks involved and the conceptions of working memory are not necessarily equivalent.

A comprehensive discussion concerning the nature of working memory is beyond the scope of the present paper, but it is a topic that has considerable potential for fruitful debate. Suffice it to say here that working memory in some form appears to be important for some aspects of arithmetic, and an approach based on a multicomponent view of working memory appears to be a fruitful way of providing insight into the nature of the cognitive processing and cognitive mechanisms on which arithmetic relies.

\section{REFERENCES}

AshCRAFT, M. H. (1992). Cognitive arithmetic: A review of data and theory. Cognition, 44, 75-106.

Ashcraft, M. H., Donley, R. D., Halas, M. H., \& VaKali, M. (1992) Working memory, automaticity, and problem difficulty. In J. I. D. Campbell (Ed.), The nature and origins of mathematical skills (pp. 301-329). Amsterdam: Elsevier.

ASHCRAFT, M. H., \& STAZYK, E. K. H. (1981). Mental addition: A test of three verification models. Memory \& Cognition, 9, 185-196.

BADDELEY, A. D. (1966). The capacity for generating information by randomization. Quarterly Journal of Experimental Psychology, 18, $119-130$.

BADDELEY, A. D. (1986). Working memory. Oxford: Oxford University Press.

BaDDELEY, A. D. (1992). Is working memory working? The fifteenth Bartlett Lecture. Quarterly Joumal of Experimental Psychology, 44, $1-31$.

Baddeley, A. D., Bressi, S., Della Sala, S., Logie, R. H., \& SPINNLER, H. (1991). The decline of working memory in Alzheimer's disease: A longitudinal study. Brain, 114, 2521-2542.

BADDELEY, A. D., \& Hitch, G. J. (1974). Working memory. In G. Bower (Ed.), The psychology of learning and motivation (Vol. 8, pp. 47-90). New York: Academic Press.

BADDELEY, A. D., LewIS, V. J., \& VAlLAR, G. (1984). Exploring the articulatory loop. Quarterly Journal of Experimental Psychology, 36, 233-252.

Baddeley, A. D., \& Lieberman, K. (1980). Spatial working memory. 
In R. S. Nickerson (Ed.), Attention and performance VIII (pp. 521539). Hillsdale, NJ: Erlbaum.

BADDELEY, A. D., \& LoGIE, R. H. (1992). Auditory imagery and working memory. In D. Reisberg (Ed.), Auditory imagery (pp. 179-197). Hillsdale, NJ: Erlbaum.

Baddeley, A. D., Logie, R. H., Bressi, S., Della Sala, S., \& SPINNLER, H. (1986). Senile dementia and working memory. Quarterly Journal of Experimental Psychology, 38A, 603-618.

Baddeley, A. D., Logie, R. H., Nimmo-Smith, I., \& Brereton, N. (1985). Components of fluent reading. Journal of Memory \& Language, 24, 119-131.

Baddeley, A. D., Thomson, N., \& Buchanan, M. (1975). Word length and the structure of short-term memory. Journal of Verbal Learning \& Verbal Behavior, 14, 575-589.

BrooKs, L. R. (1967). The suppression of visualisation by reading. Quarterly Journal of Experimental Psychology, 19, 289-299.

Campbell, J. I. D., \& ClaRK, J. M. (1988). An encoding-complex view of cognitive number processing: Comment on McCloskey, Sokol, and Goodman (1986). Journal of Experimental Psychology: General, 117, 204-214.

Campbell, J. I. D., \& Graham, D. J. (1985). Mental multiplication skill: Structure, process, and acquisition. Canadian Journal of Psychology, 39, 338-366.

ConRad, R. (1964). Acoustic confusions in immediate memory. British Journal of Psychology, 55, 75-84.

Dehaene, S. (1992). Varieties of numerical abilities. Cognition, 44, $1-42$

Dehaene, S., \& Cohen, L. (1991). Two mental calculation systems: A case study of severe acalculia with preserved approximation. Neuropsychologia, 29, 1045-1074.

Della SAlA, S., \& LoGIE, R. (1993). When working memory does not work. The role of working memory in neuropsychology. In F. Boller \& H. Spinnler (Eds.), Handbook of neuropsychology (Vol. 8, pp. 162). Amsterdam: Elsevier.

Della Sala, S., Logie, R. H., Marchetti, C., \& Wynn, V. (1991). Case studies in working memory: A case for single cases? Cortex, 27, 169-191.

ELLIS, N. C. (1992). Linguistic relativity revisited: The bilingual wordlength effect in working memory during counting, remembering numbers and mental calculation. In R. Harris (Ed.), Cognitive processes in bilinguals (pp. 137-156). Amsterdam: Elsevier.

Ellis, N. C., \& HenNelley, R. A. (1980). A bilingual word length effect: Implications for intelligence testing and the relative ease of mental calculation in Welsh and English. British Journal of Psychology, 71, 43-52.

Engle, R. W., Cantor, J., \& Carullo, J. (1992). Individual differences in working memory and comprehension: A test of four hypotheses. Journal of Experimental Psychology: Learning, Memory, \& Cognition, 18, 972-992.

EvaNs, F. J. (1978). Monitoring attention deployment by random number generation: An index to measure subjective randomness. Bulletin of the Psychonomic Society, 12, 35-38.

Fabiani, M., Buckley, J., Gratton, G., Logie, R. H., Coles, M. G. H., \& DonchIN, E. (1989). The training of complex task performance. Acta Psychologica, 71, 259-299.

Farmer, E. W., Berman, J. V. F., \& Fletcher, Y. L. (1986). Evidence for a visuo-spatial scratch-pad in working memory. Quarterly Journal of Experimental Psychology, 38A, 675-688.

Gallistel, C. R., \& GELMAN, R. (1992). Preverbal and verbal counting and computation. Cognition, 44, 43-74.

GEARY, D. C., \& WIDAMAN, K. F. (1987). Individual differences in cognitive arithmetic. Journal of Experimental Psychology: General, 116, 154-171.

Geary, D. C., \& Widaman, K. F. (1992). Numerical cognition: On the convergence of componential and psychometric models. Intelligence, 16, 47-80.

GiLhooLy, K. J. (1988). Thinking: Directed, undirected and creative (2nd ed.). London: Academic Press.

GILHOOLY, K. J., LOGIE, R. H., WETHERICK, N., \& WYNN, V. (1993), Working memory and strategies in syllogistic reasoning tasks. Memory \& Cognition, 21, 115-124.
Glasgow, J., \& PaPadias, D. (1992). Computational imagery. Cognitive Science, 16, 355-394.

GonZalez, E. G., \& Kolers, P. A. (1982). Mental manipulation of arithmetic symbols. Journal of Experimental Psychology: Learning, Memory, \& Cognition, 8, 308-319.

GRAHAM, D. J. (1987). An associative retrieval model of arithmetic memory: How children learn to multiply. In J. Sloboda \& D. Rogers (Eds.), Cognitive processes in mathematics (pp. 123-141). Oxford: Oxford Science.

HAYES, J. R. (1973). On the function of visual imagery in elementary mathematics. In W. G. Chase (Ed.), Visual information processing (pp. 177-214). New York: Academic Press.

Healy, A. F., \& NaIRNE, J. S. (1985). Short-term memory processes in counting. Cognitive Psychology, 17, 417-444.

HrTCH, G. J. (1978). The role of short-term working memory in mental arithmetic. Cognitive Psychology, 10, 302-323.

Hitch, G. J., Cundick, J., Haughey, M., Pugh, R., \& Wright, H. (1987). Aspects of counting in children's arithmetic. In J. Sloboda \& D. Rogers (Eds.), Cognitive processes in mathematics (pp. 2641). Oxford: Oxford Science Publications.

Hitch, G. J., \& MCAuley, E. (1991). Working memory in children with specific arithmetical difficulties. British Journal of Psychology, 82, 375-386.

Hoosain, R., \& SaliLI, F. (1988). Language differences, working memory and mathematical ability. In M. M. Gruneberg, P. E. Morris, \& R. N. Sykes (Eds.), Practical aspects of memory: Current research and issues (Vol. 2, pp. 512-517). London: Wiley.

HUNT, E., \& LaNSMAN, M. (1982). Individual differences in attention. In R. Sternberg (Ed.), Advances in the psychology of intelligence (Vol. 1, pp. 207-254). Hillsdale, NJ: Erlbaum.

Johnson-LAIRd, P. N. (1983). Mental models. Cambridge: Cambridge University Press.

JohnSON-LAIRD, P. N., \& BYRNE, R. (1991). Deduction. Hove, U.K.: Erlbaum.

Johnstone, A. H., \& AL-NAEME, F. F. (1991). Room for scientific thought? International Journal of Science Education, 13, 187192.

Just, M. A., \& CARPEnTER, P. A. (1992). A capacity theory of comprehension: Individual differences in working memory. Psychological Review, 99, 122-149.

LEVY, B. A. (1971). The role of articulation in auditory and visual short-term memory. Journal of Verbal Learning \& Verbal Behavior, 10, 123-132.

LoGIE, R. H. (1986). Visuo-spatial processing in working memory. Quarterly Journal of Experimental Psychology, 38A, 229-247.

LOGIE, R. H. (1989). Characteristics of visual short-term memory. European Journal of Cognitive Psychology, 1, 275-284.

LoGIE, R. H. (1991). Visuo-spatial short-term memory: Visual working memory or visual buffer? In C. Cornoldi \& M. McDaniel (Eds.), Imagery and cognition (pp. 77-102). Berlin: Springer-Verlag.

LoGIE, R. H. (1993). Working memory in everyday cognition. In G. M. Davies \& R. H. Logie (Eds.), Memory in everyday life (pp. 173218). Amsterdam: Elsevier.

LOGIE, R. H., \& BADDELEY, A. D. (1987). Cognitive processes in counting. Journal of Experimental Psychology, 13, 310-326.

LOGIE, R. H., \& BADDELEY, A. D. (1990). Imagery and working memory. In P. Hampson, D. Marks, \& J. Richardson (Eds.), Imagery: Current developments (pp. 103-128). London: Routledge \& Kegan Paul.

Logie, R. H., Baddeley, A. D., Mane, A., Donchin, E., \& SHEPTAK, R. (1989). Working memory and the analysis of a complex skill by secondary task methodology. Acta Psychologica, 71, 53-87.

LOGIE, R. H., \& MARCHETTI, C. (1991). Visuo-spatial working memory: Visual, spatial or central executive? In R. H. Logie \& M. Denis (Eds.), Mental images in human cognition (pp. 105-115). Amsterdam: Elsevier.

Logie, R. H., \& SalWay, A. F. (1990). Working memory and modes of thinking: A secondary task approach. In K. Gilhooly, M. Keane, R. Logie, \& G. Erdos (Eds.), Lines of thinking (Vol. 2, pp. 99-113). Chichester: Wiley. 
Logie, R. H., Zucco, G., \& BADDELEY, A. D. (1990). Interference with visual short-term memory. Acta Psychologica, 75, 55-74.

MATTHEWS, W. A. (1983). The effects of concurrent secondary tasks on the use of imagery in a free recall task. Acta Psychologica, 53, 231-241.

McCarthy, R. A., \& WarRington, E. K. (1990). Cognitive neuropsychology: A clinical introduction. London: Academic Press.

MCCloskeY, M. (1992). Cognitive mechanisms in numerical processing: Evidence from acquired dyscalculia. Cognition, 44, 107-157.

McCloskey, M., Harley, W., \& Sokol, S. (1991). Models of arithmetic fact retrieval: An evaluation in light of findings from normal and brain damaged subjects. Journal of Experimental Psychology. Learning, Memory, \& Cognition, 17, 377-397.

McCloskey, M., Sokol, S., \& Goodman, R. A. (1986). Cognitive processes in verbal-number production: Inferences from the performance of brain-damaged subjects. Journal of Experimental Psychology: General, 115, 307-330.

MCLEOD, P. (1977). A dual task response modality effect: Support for multi-processor models of attention. Quarterly Journal of Experimental Psychology, 29, 651-667.

MILNER, B. (1963). Effects of different brain lesions on card sorting Archives of Neurology, 9, 90-100.

MORAY, N. (1967). When attention is limited: A survey and a model Acta Psychologica, 27, 84-92.

MOYER, R. S., \& LANDAUER, T. K. (1967). Time required for judgements of numerical inequality. Nature, 215, 1519-1520.

MURRAY, D. (1968). Articulation and acoustic confusability in shortterm memory. Journal of Experimental Psychology, 78, 679-684.

NAIRNE, J. S., \& Healy, A. F. (1983). Counting backwards produces systematic errors. Journal of Experimental Psychology: General, $112,37-40$

Naveh-Benjamin, M., \& Ayres, T. J. (1986). Digit span, reading rate, and linguistic relativity. Quarterly Journal of Experimental Psychology, 38, 739-751.

NAVON, D., \& Gopher, D. (1979). On the economy of the human processing system. Psychological Review, 86, 214-255.

Newell, A., \& Simon, H. A. (1972). Human problem solving. Englewood Cliffs, NJ: Prentice-Hall.

QuinN, J. G., \& RaLsTon, G. E. (1986). Movement and attention in visual working memory. Quarterly Journal of Experimental Psychology, 38A, 689-703.

REISBERG, D., \& LOGIE, R. H. (1993). The in's and out's of visual working memory: Overcoming the limits on learning from imagery. In B. Roskos-Ewoldsen, M. J. Intons-Peterson, \& R. Anderson (Eds.), Imagery, creativity, and discovery: A cognitive approach (pp. 3976). Amsterdam: Elsevier.

RESTLE, F. (1970). Speed of adding and comparing numbers. Journal of Experimental Psychology, 83, 274-278.

Reyna, V., \& Brainerd, C. (1993). Fuzzy reasoning and mathematics in the classroom. In G. M. Davies \& R. H. Logie (Eds.), Memory in everyday life (pp. 91-119). Amsterdam: Elsevier

SAARILUOMA, P. (1991). Visuo-spatial interference and apperception in chess. In R. H. Logie \& M. Denis (Eds.), Mental images in human cognition (pp. 83-94). Amsterdam: Elsevier.

Salamé, P., \& Baddeley, A. D. (1982). Disruption of short-term memory by unattended speech: Implications for the structure of working memory. Journal of Verbal Learning \& Verbal Behavior, 21, $150-164$.

SALWAY, A. F. (1991). Random generation in the working memory dual-task paradigm. Unpublished doctoral dissertation, University of Aberdeen, Aberdeen, Scotland.

Shallice, T. (1988). From neuropsychology to mental structure. Cambridge: Cambridge University Press.
SIEGLER, R. S. (1987). Strategy choices in subtraction. In J. Sloboda \& D. Rogers (Eds.), Cognitive processes in mathematics (pp. 81106). Oxford: Oxford Science Publications.

Smyth, M. M., \& Pendleton, L. R. (1989). Working memory for movements. Quarterly Journal of Experimental Psychology, 41A, 235-250.

Sokol, S. M., Goodman-Schulman, R., \& McCloskey, M. (1989). In defense of a modular architecture for the number-processing system: Reply to Campbell and Clark. Journal of Experimental Psychology: General, 118, 105-110.

SoKol, S., McCloskey, M., Cohen, N. J., \& Aliminosa, D. (1991). Cognitive representations and processes in arithmetic: Inferences from the performance of brain damaged subjects. Journal of Experimental Psychology: Learning, Memory, \& Cognition, 17, 355376.

Treisman, M., \& Faulkner, A. (1987). Generation of random sequences by human subjects: Cognitive operations or psychophysical processes. Journal of Experimental Psychology: General, 116, 337-355.

TuRNER, M. L., \& ENGLE, R. W. (1989). Is working memory capacity task dependent? Journal of Memory \& Language, 28, 127-154.

WiCKeNS, C. D., \& LiU, Y. (1988). Codes and modalities in multiple resources: A success and a qualification. Human Factors, 30, 599616.

Wickens, C. D., \& WeIngarTner, A. (1985). Process control monitoring: The effects of spatial and verbal ability and concurrent task demand. In R. E. Eberts \& C. G. Eberts (Eds.), Trends in ergonomics and human factors II (pp. 25-32). Amsterdam: Elsevier, North-Holland.

Widaman, K. F., Geary, D. C., Cormier, O., \& Little, T. D. (1989). A componential model of mental addition. Journal of Experimental Psychology: Learning, Memory, \& Cognition, 15, 898919.

Yee, P. L., Hunt, E., \& Pellegrino, J. W. (1991). Coordinating cognitive information: Task effects and individual differences in integrating information from several sources. Cognitive Psychology, 23, 615-680.

YEH, Y. Y., \& WICKENS, C. D. (1988). The dissociation of subjective measures of mental workload and performance. Human Factors, 30 , 111-120.

\section{NOTE}

1. Just and Carpenter (1992) view working memory as a single flexible resource that provides both storage and processing functions, particularly in language comprehension. They specifically mention that their concept of working memory corresponds fairly closely to the central executive system in the Baddeley and Hitch (1974; Baddeley, 1986) model, and they see the articulatory loop as being a system that is quite independent of working memory. It is certainly clear that this more restricted view of working memory serves processing and storage functions in tasks other than language comprehension (see, e.g., Baddeley, Logie, Nimmo-Smith, \& Brereton, 1985; Engle et al., 1992; Turner \& Engle, 1989). Our view is that this distinction is simply a matter of how the terminology is used, and we feel that it is more useful to employ the term working memory to refer to a coherent collection of components that act in concert and that are coordinated by a central flexible resource.

(Manuscript received March 8, 1993; revision accepted for publication September 8, 1993.) 